\title{
Flow-Injection Spectrophotometric Determination of Nitrite and Nitrate in Biological Samples
}

\author{
Keiro Higuchi and Shoji MoтомIzU \\ Department of Chemistry, Faculty of Science, Okayama University, Tsushima-naka, Okayama 700-8530, Japan
}

\begin{abstract}
Nitrite and nitrate in biological samples can act as an indicator of nitric oxide generated in vivo and have attracted a lot of attention as a messenger of diverse physiological processes. For the determination of such nitrogen oxides, a simple and sensitive flow-injection method coupled with a successful pretreatment method was developed. Nitrite and nitrate in sample solution were injected into a carrier solution containing EDTA and ammonium buffer, and flowed into the copperized cadmium $(\mathrm{Cd} / \mathrm{Cu})$ reduction column installed on-line. Here the nitrate was reduced to nitrite, and then nitrite was determined spectrophotometrically on the basis of a diazotization/coupling reaction. The detection limits for nitrite and nitrate were $5 \times 10^{-8} \mathrm{M}$, and the sampling rate was about 40 samples per hour for nitrate determination. The biological samples, such as serum, plasma and cell culture medium, were deproteinized using a batchwise $\mathrm{NaOH}-\mathrm{ZnSO}_{4}$ method before FIA measurement. The $\mathrm{NaOH}-\mathrm{ZnSO}_{4}$ deproteinization method was very effective in term of the recovery of nitrate and the maintenance of the reduction efficiency of the $\mathrm{Cd} / \mathrm{Cu}$ column. The relative standard deviations were 2.1 $3.1 \%$, and the recoveries were $95-100 \%$ for the determination of nitrite and nitrate in serum samples through the whole procedure. In the case of cell culture medium, the proposed deproteinization was especially effective for removing the interfering amino acids containing sulfur atom by using the reaction between $\mathrm{Zn}^{2+}$ in deproteinization agent and sulfur atom in analytical substances.
\end{abstract}

Keywords Nitric oxide, nitrite and nitrate determination, flow injection analysis, copperized cadmium reduction column, deproteinization, biological samples

Nitrogen oxides $\left(\mathrm{NO}_{x}\right)$ involving nitric oxide $(\mathrm{NO})$, nitric dioxide $\left(\mathrm{NO}_{2}\right)$, nitrite ion $\left(\mathrm{NO}_{2}^{-}\right)$and nitrate ion $\left(\mathrm{NO}_{3}{ }^{-}\right)$have been considered as a suspected carcinogen, an environmental pollutant and a precursor of acid rain, respectively. Recently, nitric oxide (NO), which is generated by the action of nitric oxide synthetase in vivo, has attracted a lot of attention as a messenger of diverse physiological processes such as smooth muscle relaxation, platelet aggregation inhibition, neurotransmission and immune regulation. ${ }^{1-4} \mathrm{NO}$ is a short lived ${ }^{5}$ unstable radical molecule; therefore, it is difficult to determine directly. NO, however, is almost completely converted into nitrite and nitrate in vivo. It seems appropriate, therefore, to estimate generated NO levels by determining nitrite and nitrate in biological samples. ${ }^{6}$

A number of flow-injection methods for the determination of nitrite and nitrate have been reported so far, most of them are based on a diazotization/coupling reaction. ${ }^{7-12}$ However, very little information has been available for biological samples, because there is too little to determine a trace amount of nitrite and nitrate and no possibilities for successful pretreatments of biological samples. Green et al. ${ }^{13}$ reported the determination of nitrite and nitrate in biological fluids. In this method, the cation-exchange resin column was attached to the on-line system in order to trap interfering substances. The detection limit was $1 \times 10^{-6} \mathrm{M}$, which was not enough for the biological samples because it was not effective to trap interfering substances practically, and it was quite complicated. Furthermore, the deproteinization procedure of samples was also complicated; it often caused serious experimental errors. The recoveries of nitrite and nitrate during the deproteinization operation were less than sufficient for the analysis of cell culture mediums.

In this work, an improved spectrophotometric method based on a diazotization/coupling reaction was applied to the determination of trace amounts of nitrite and nitrate in biological samples. Here nitrate was reduced quantitatively to nitrite by the on-line copperized cadmium column, and the deproteinization method using both $\mathrm{NaOH}$ and $\mathrm{ZnSO}_{4}$ was applied successfully to the pretreatment of biological samples before FIA measurement.

\section{Experimental}

\section{Apparatus}

The flow system used in this work is shown schematically in Fig. 1. A double-plunger micro pump (Model 201; FLOM Corp.) was used for a carrier solution and a color-developing reagent solution. The absorbance was measured with a double-beam spectrophotometer with a $10-\mathrm{mm}$ flow cell $(8 \mu \mathrm{l})$ (Model S-3250; Soma Kogaku), the peaks being recorded with a recorder 


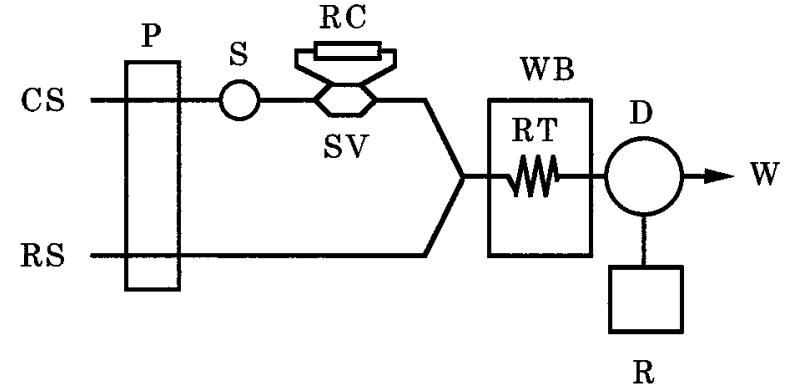

Fig. 1 Schematic FIA diagram for the determination of nitrite and nitrate. CS: carrier solution $\left(\mathrm{EDTA}+\mathrm{NH}_{4} \mathrm{Cl}\right)$; RS: reagent solution (SA+NEDA); P: double-plunger micro pump (each

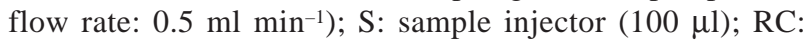
$\mathrm{Cd} / \mathrm{Cu}$ reduction column $(2 \mathrm{~mm}$ i.d. $\times 15 \mathrm{~cm})$; $\mathrm{SV}$ : column switching valve; RT: reaction tubing $(0.5 \mathrm{~mm}$ i.d. $\times 2 \mathrm{~m})$; WB: water bath $\left(50^{\circ} \mathrm{C}\right)$; D: spectrophotometric detector $(540 \mathrm{~nm})$; $\mathrm{R}$ : recorder; $\mathrm{W}$ : waste.

(Model DR1212; Okuradenki). The sample solution $(100 \mu \mathrm{l})$ was injected via a six-way injection valve into the carrier stream. A copperized cadmium $(\mathrm{Cd} / \mathrm{Cu})$ reduction column, which was installed on-line, was made from a glass column $(2 \mathrm{~mm}$ i.d. $\times 15 \mathrm{~cm})$ filled with the copperized cadmium (particle size: $0.5-2.0$ $\mathrm{mm})$.

\section{Reagents}

All reagents used were of analytical-reagent grade and were used without further purification. Water purified with Milli-Q Labo was used for preparing all solutions and diluting them.

Carrier solution: ammonium chloride (3 g) and EDTA (disodium salt, dihydrate) $(0.7 \mathrm{~g})$ were dissolved in water, the $\mathrm{pH}$ was adjusted to 8.2 with $\mathrm{NaOH}$, and the solution was diluted to 11 with water.

Color-developing reagent solution: sulfanilamide (1 g) and $N$-1-naphthylethylenediamine $(0.1 \mathrm{~g})$ were dissolved in 11 of $0.1 \mathrm{M} \mathrm{HCl}$, which was freshly prepared daily.

Nitrite standard solution: a stock solution $\left(1 \times 10^{-3} \mathrm{M}\right)$ was prepared by dissolving $0.0690 \mathrm{~g}$ of sodium nitrite dried at $105^{\circ} \mathrm{C}$ for $3 \mathrm{~h}$ in water to give a 1-1 solution. Working standard solutions were freshly prepared by accurate dilution of the stock solution.

Nitrate standard solution: a stock solution $\left(1 \times 10^{-3} \mathrm{M}\right)$ was prepared by dissolving $0.1011 \mathrm{~g}$ of potassium nitrate dried at $105^{\circ} \mathrm{C}$ for $3 \mathrm{~h}$ in water to give a $1-1$ solution. Working standard solutions were freshly prepared by accurate dilution of the stock solution.

Deproteinization solutions: five grams of zinc sulfate (seven hydrate) was dissolved into $100 \mathrm{ml}$ of water $(5 \%$ $\left.\mathrm{ZnSO}_{4}\right)$. Sodium hydroxide solution $(0.3 \mathrm{M})$ was prepared. These solutions were used for the deproteinization of serum, plasma and cell culture medium samples.

\section{Deproteinization procedure}

Serum $(100 \mu \mathrm{l})$ was added to a mixture of $400 \mu \mathrm{l}$ of water and $300 \mu \mathrm{l}$ of $0.3 \mathrm{M} \mathrm{NaOH}$ solution. The solu- tion was kept for $5 \mathrm{~min}$ at room temperature; then 300 $\mu \mathrm{l}$ of $5 \% \mathrm{ZnSO}_{4}$ solution was added. The mixture was allowed to stand for $5 \mathrm{~min}$ after shaking and was then centrifuged at $6400 \mathrm{rpm}$ for $10 \mathrm{~min}$ at room temperature. The supernatant was injected into the FIA system. Plasma samples were also deproteinized by the same procedure. For cell culture medium samples, $300 \mu \mathrm{l}$ of sample was added to $300 \mu \mathrm{l} 0.3 \mathrm{M} \mathrm{NaOH}$ solution and then $300 \mu \mathrm{l}$ of $5 \% \mathrm{ZnSO}_{4}$ solution was added.

\section{Analytical procedure}

Pretreated sample solutions $(100 \mu \mathrm{l})$ were injected into the carrier stream containing EDTA and ammonium buffer ( $\mathrm{pH}$ 8.2), and flowed into the $\mathrm{Cd} / \mathrm{Cu}$ reduction column, where nitrate was reduced to nitrite, and then it merged with the color-developing reagent solution. A diazotization/coupling reaction occurred during the flowing in polytetrafluoroethylene (PTFE) tubing, and formed the purple azo compound. The total amount of nitrite and nitrate was determined by measuring its absorbance at $540 \mathrm{~nm}$. By changing the column switching valve, nitrite was measured separately from nitrate without the reduction. Nitrate could be calculated by subtracting the amount of nitrite from the total amount of nitrite and nitrate.

\section{Results and Discussion}

\section{Spectrophotometric detection of nitrite and nitrate}

Most of the flow-injection determination methods of nitrate have been based on the reduction of nitrate to nitrite, which has been determined by spectrophotometry of an azo dye formed by diazotization/coupling reaction. In the previous study ${ }^{14}$ sulfanilamide (SA) and $N$-1-naphthylethylenediamine (NEDA) were used as color-developing reagents for the determination of nitrite and nitrate in environmental water samples. In order to improve the detection limit, the effect of the temperature of the reaction tubing on the diazotization/coupling reaction was examined by varying the temperature of the water bath from $30^{\circ} \mathrm{C}$ to $70^{\circ} \mathrm{C}$. The peak height increased with an increase in temperature, and reached almost to the maximum at $50^{\circ} \mathrm{C}$. Therefore, the temperature of the water bath was set up $50^{\circ} \mathrm{C}$. The effect of the length of the reaction tubing was examined by varying it from $1 \mathrm{~m}$ to $5 \mathrm{~m}$ using PTFE tubing $(0.5 \mathrm{~mm}$ i.d. $)$ at the temperature of the water bath at $50^{\circ} \mathrm{C}$. The peak height reached almost to the maximum and constant in the length of $2 \mathrm{~m}$. Considering the sampling rate, we adopted the reaction tubing length of $2 \mathrm{~m}$. The effect of the flow rate of the carrier and the reagent solutions were examined by varying their flow rate from $1 \mathrm{ml} / \mathrm{min}$ to $1.8 \mathrm{ml} / \mathrm{min}$. The peak height decreased with the increasing flow rate. Considering the sensitivity and the sampling rate, we adopted the flow rate of $1 \mathrm{ml} / \mathrm{min}$.

Usually the reduction of nitrate to nitrite is carried out by passing sample solutions through a $\mathrm{Cd} / \mathrm{Cu}$ column. 
In an FIA system proposed in this work, the reduction efficiency was found to be very high and more than 98\% using the proposed carrier solution containing EDTA and ammonium buffer ( $\mathrm{pH}$ 8.2). Furthermore, it was unnecessary to reactivate and wash the $\mathrm{Cd} / \mathrm{Cu}$. The reduction efficiency could be kept at more than $98 \%$ by only filling a column with the carrier solution containing EDTA at pH 8.2 after use. It was very important and necessary for maintaining the quantitative reduction that EDTA was involved in the carrier solution, because the surface of $\mathrm{Cd} / \mathrm{Cu}$ particles was washed out by the formation of a Cd-EDTA complex and an active surface could appear at any time. The effect of the length of $\mathrm{Cd} / \mathrm{Cu}$ column ( $2 \mathrm{~mm}$ i.d.) was examined with $10 \mathrm{~cm}, 15 \mathrm{~cm}$ and $20 \mathrm{~cm}$. There was no difference in the reduction efficiency of nitrate to nitrite. Considering the endurance of the reduction efficiency, the $\mathrm{Cd} / \mathrm{Cu}$ column we adopted the length of 15 $\mathrm{cm}$ in this work. The results obtained by the proposed FIA method using SA, NEDA and the $\mathrm{Cd} / \mathrm{Cu}$ on-line reduction column were found to have good correlation with the results obtained by the batchwise spectrophotometric method. ${ }^{15}$ Therefore, in this work, the SANEDA method and $\mathrm{Cd} / \mathrm{Cu}$ on-line reduction column were also adopted for the determination of nitrite and nitrate in biological samples.

Calibration graph and detection limit for nitrite and nitrate in standard solution

Calibration graphs for nitrite and nitrate were obtained by using the proposed system and experimental conditions. Figures 2 and 3 show the flow signals for the calibration graphs and reproducibility test. It is proved, by comparing the peak height of nitrate with that of nitrite, that the reduction efficiency of nitrate to nitrite was almost $100 \%$ in various concentrations. The calibration graphs were linear over the ranges of 0 to $10 \times 10^{-6} \mathrm{M}$ and 0 to $10 \times 10^{-7} \mathrm{M}$ of nitrite and nitrate individually. The reproducibility of the peak height was very good, and the relative standard deviations of twenty injections were $0.14 \%$ and $1.29 \%$ for the concentrations of nitrate $6 \times 10^{-6} \mathrm{M}$ and $4 \times 10^{-7} \mathrm{M}$, respectively. The detection limit corresponding to the signal to noise ratio $(S / N)$ of 3 was found to be about $5 \times 10^{-8}$ $\mathrm{M}$ of nitrite and nitrate respectively, which was enough to determine nitrate and nitrate in biological samples. The sampling rate was about 40 samples/h.

\section{Determination of nitrite and nitrate in urine samples}

It was necessary for the determination of nitrite and nitrate in biological samples to carry out the pretreatment such as deproteinization before FIA measurement, because proteins and the other coexisting biological substances interfered with the reduction of nitrate and the color-developing reaction. Urine samples were only diluted to 50-200 times with the carrier solution containing EDTA and the deproteinization procedure was unnecessary, because the concentrations of nitrite and nitrate in urine were generally $10^{-4} \mathrm{M}$ levels and

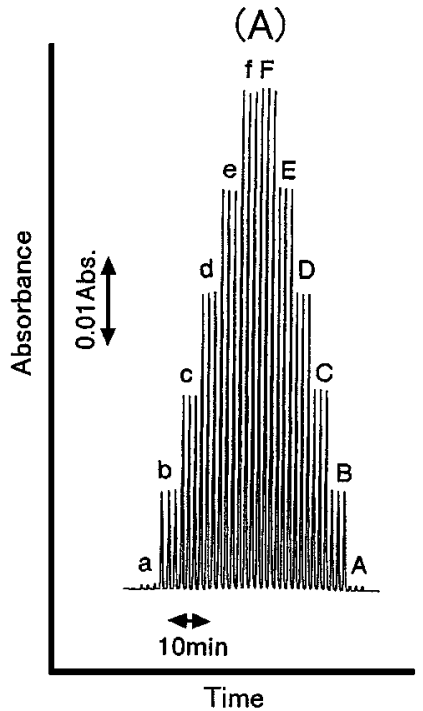

(B)

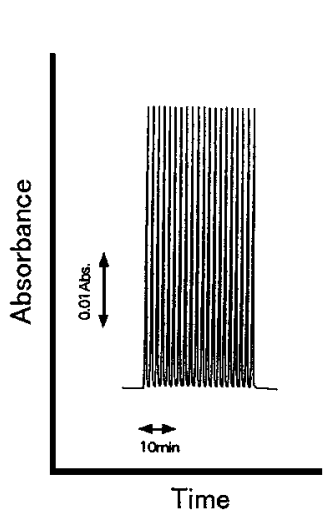

Fig. 2 Flow signals for the calibration graph and reproducibility test of nitrite and nitrate. (A) $\left[\mathrm{NO}_{2}^{-}\right] / 10^{-6} \mathrm{M}: \mathrm{a}, 0 ; \mathrm{b}, 2 ; \mathrm{c}$, 4; d, 6; e, 8; f, 10; $\left[\mathrm{NO}_{3}^{-}\right] / 10^{-6} \mathrm{M}: \mathrm{A}, 0 ; \mathrm{B}, 2 ; \mathrm{C}, 4 ; \mathrm{D}, 6$; E, 8; F, 10. (B) $\left[\mathrm{NO}_{3}^{-}\right], 6 \times 10^{-6} \mathrm{M}$.

(A)
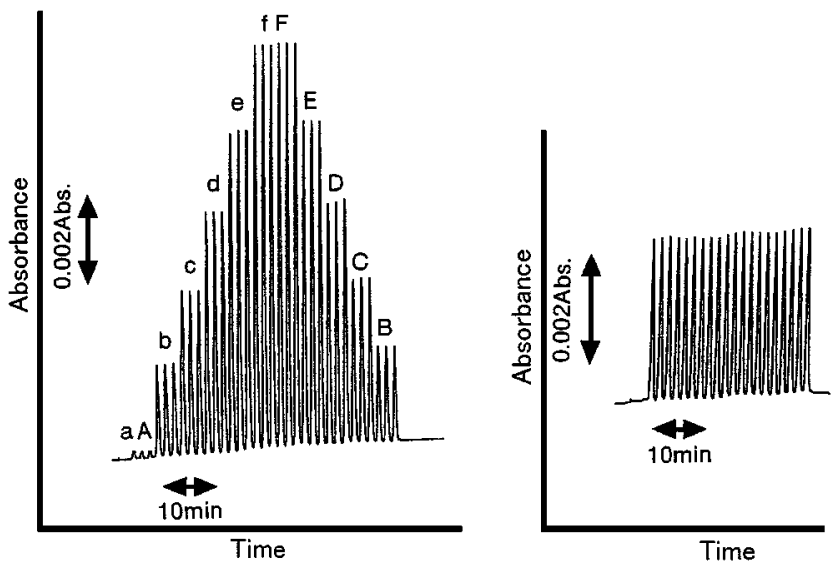

Fig. 3 Flow signals for the calibration graph and reproducibility test of nitrite and nitrate. (A) $\left[\mathrm{NO}_{2}{ }^{-}\right] / 10^{-7} \mathrm{M}: \mathrm{a}, 0 ; \mathrm{b}, 2 ; \mathrm{c}$, 4; d, 6; e, 8; f, 10; $\left[\mathrm{NO}_{3}^{-}\right] / 10^{-7} \mathrm{M}: \mathrm{A}, 0 ; \mathrm{B}, 2 ; \mathrm{C}, 4 ; \mathrm{D}, 6$; E, 8; $\mathrm{F}, 10$. (B) $\left[\mathrm{NO}_{3}^{-}\right], 4 \times 10^{-7} \mathrm{M}$.

the interferences were effectively eliminated by 50 200 times dilutions. The relative standard deviations of ten measurements of nitrite and nitrate in urine samples were found to be $1.2-2.6 \%$ and the recoveries were $97-100 \%$, as shown in Tables 1 and 2. Generally, the concentrations of nitrate were found to be 10 to 100 times higher than that of nitrite in urine, serum and plasma samples by changing the column switching valve in the proposed FIA system.

Determination of nitrite and nitrate in serum and plasma samples

When the serum and plasma samples were injected 
Table 1 Reproducibility tests for the determination of total amount of nitrite and nitrate in urine samples

\begin{tabular}{ccc}
\hline Pretreatment & Concentration $^{\mathrm{a}} / 10^{-4} \mathrm{M}$ & $\mathrm{RSD}, \%$ \\
\hline Direct dilution $^{\mathrm{b}}$ & $16.5 \pm 0.44$ & 2.64 \\
Stepwise dilution $^{\mathrm{c}}$ & $15.4 \pm 0.32$ & 2.08 \\
Deproteinization $^{\mathrm{d}}$ & $16.0 \pm 0.19$ & 1.17
\end{tabular}

a. Mean values of ten measurements.

b. Sample was diluted to 100 times with the carrier solution.

c. Sample was diluted twice by stepwise to 10 times.

d. Sample was deproteinized by the $\mathrm{NaOH}-\mathrm{ZnSO}_{4}$ method and then consequently was diluted to 10 times with the carrier solution.

into the proposed FIA system directly or with about 10 times dilution, nitrate was not recovered sufficiently and the reduction efficiency of nitrate decreased to less than $70 \%$ after only a few injections of samples. This indicates that it is necessary to carry out the deproteinization before FIA measurement for the determination of nitrite and nitrate in serum and plasma samples, because proteins and the other coexisting biological substances interfered with the reduction of nitrate and the color-developing reaction. When serum and plasma samples were deproteinized by using perchloric acid, which was usually used in the pretreatment of biological samples, the recovery of nitrate was not sufficient. In the case of using trichloroacetic acid, the colordeveloping reaction was interfered with from the oxidizing impurity existing in tricloroacetic acid. If we used ethanol as deproteinization agent, the recovery of nitrate and the color-developing reaction were not also sufficient. Nitrite ion is known to be more stable in alkaline solutions than in acidic solutions. Therefore, serum and plasma samples were deproteinized by the Somogyi and Nelson ${ }^{16,17}$ method using $\mathrm{NaOH}$ and $\mathrm{ZnSO}_{4}$, which have been rarely used for the determination of blood glucose. This was the most effective method with respect to the reproducibility and sufficient recovery and the endurance of reduction efficiency of $\mathrm{Cd} / \mathrm{Cu}$ column.

By the proposed deproteinization procedure of the standard solution of $100 \times 10^{-6} \mathrm{M}$ nitrate, the relative standard deviation of ten measurements was found to be $0.9 \%$. In serum samples, the relative standard deviations were found to be $2.1-3.1 \%$ and the recoveries were $95-100 \%$ for the determination of nitrite and nitrate in serum through the whole procedure with the concentration range from $8.7 \times 10^{-6} \mathrm{M}$ to $116 \times 10^{-6} \mathrm{M}$. Figure 4 shows the results for standard addition method using serum samples. The graphs appeared to be well linear and the slopes of lines were found to be almost same as that of the standard solution. These results indicate that the added nitrates were recovered quantitatively by the $\mathrm{NaOH}-\mathrm{ZnSO}_{4}$ deproteinization. During the measurements of pretreated samples, the reduction efficiency of nitrate to nitrite was found to remain more than $98 \%$ for at least 3000 samples by flowing the car-
Table 2 Recovery tests for the determination of total amount of nitrite and nitrate in urine samples

\begin{tabular}{ccccc}
\hline Sample & $\begin{array}{c}\text { Concentration/ } \\
10^{-4} \mathrm{M}\end{array}$ & $\begin{array}{c}\text { Added/ } \\
10^{-4} \mathrm{M}\end{array}$ & $\begin{array}{c}\text { Found/ } \\
10^{-4} \mathrm{M}\end{array}$ & $\begin{array}{c}\text { Recovery, } \\
\%\end{array}$ \\
\hline 1 & 6.3 & 4.0 & 10.4 & 101 \\
2 & 9.7 & 4.0 & 13.3 & 97 \\
3 & 16.5 & 4.0 & 21.1 & 98 \\
\hline
\end{tabular}

Sample was diluted to 100 times with the carrier solution before analysis.

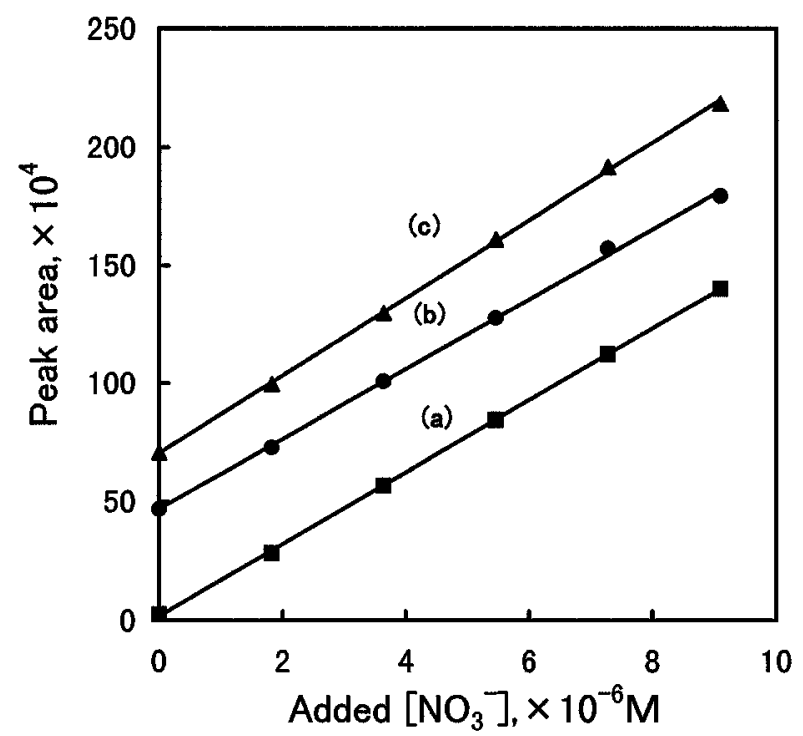

Fig. 4 Calibration graphs for the standard addition method with using serum samples by the $\mathrm{NaOH}-\mathrm{ZnSO}_{4}$ deproteinization. (a), standard solution of nitrate; (b), human serum sample 1; (c), human serum sample 2.

rier solution containing EDTA and by filling the column with the carrier solution after use.

\section{Determination of nitrite and nitrate in cell culture medium samples}

When the cell culture medium samples were injected into the proposed FIA system after diluting the sample to two times with water, the reduction efficiency of nitrate fell by ten percent with a few injections. A lot of amino acids exist in a typical cell culture medium. The interference from amino acids which coexisted in cell culture medium with the determination of nitrite and nitrate was examined. As a result, most of amino acids did not interfere with the determination of nitrite and nitrate. Figure 5 shows the flow signals for continuous injections of the nitrate standard solution containing L-phenylalanine as a typical amino acid. The flow signals obtained showed no interference from L-phenylalanine. However, L-cystine, which was contained usually in cell culture medium, interfered with the reduction of nitrate to nitrite. This is probably because the sulfur atom in L-cystine reacts with cadmium in the reduction column and then formed $\mathrm{Cd}-\mathrm{S}$, which can 
cover the surface of active cadmium. Consequently the reduction efficiency of nitrate decreased less than $80 \%$ after ten injections of the standard solution containing L-cystine. In addition, nitrate was not recovered quantitatively (Fig. 6A). In order to prevent the interference from L-cystine, the cation exchange resin $(\mathrm{AG} 50 \mathrm{~W}$ X8, 200 - 400 mesh, $\mathrm{H}$ form, BIO-RAD) was added to the standard solutions containing L-cystine. L-Cystine was found to be adsorbed on the cation exchange

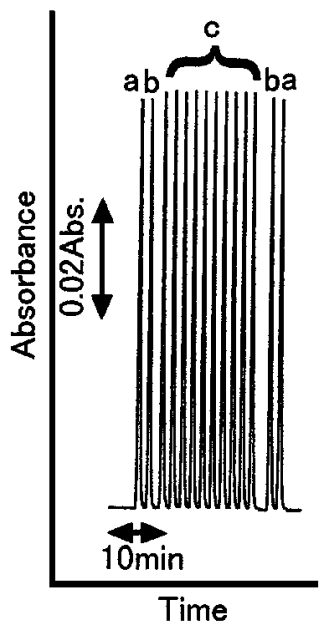

Fig. 5 Flow signals for the continuous injections of nitrate standard solution containing L-phenylalanine. (a): $\left[\mathrm{NO}_{2}{ }^{-}\right]=10 \times 10^{-6} \mathrm{M} ;(\mathrm{b}):\left[\mathrm{NO}_{3}^{-}\right]=10 \times 10^{-6} \mathrm{M} ;(\mathrm{c}):\left[\mathrm{NO}_{3}{ }^{-}\right]=$ $10 \times 10^{-6} \mathrm{M}$ containing $1 \times 10^{-3} \mathrm{M}$ of L-phenylalanine.
(A)

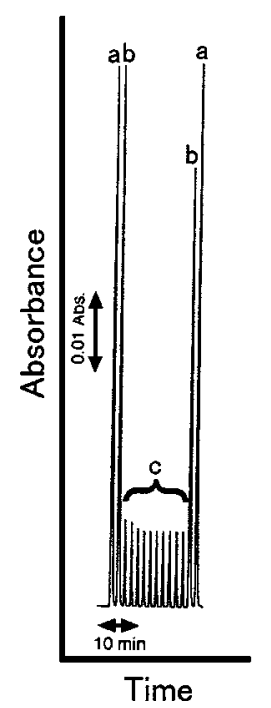

(B)

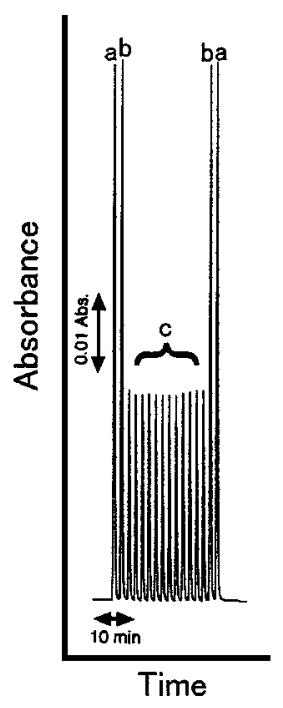

Fig. 6 Flow signals for the continuous injections of nitrate standard solution containing L-cystine. (A) without the $\mathrm{NaOH}-\mathrm{ZnSO}_{4}$ deproteinization method; (B) with the $\mathrm{NaOH}-\mathrm{ZnSO}_{4}$ deproteinization method; (a): $\left[\mathrm{NO}_{2}^{-}\right]=10 \times 10^{-6}$ $\mathrm{M}$; (b): $\left[\mathrm{NO}_{3}{ }^{-}\right]=10 \times 10^{-6} \mathrm{M}$; (c): $10 \times 10^{-6} \mathrm{M}$ of nitrate containing $1 \times 10^{-3} \mathrm{M}$ of L-cystine was diluted to 3 times with water in the case of (A) or with deproteinization agent in the case of (B). resign, so the amount of L-cystine in the supernatant of that solution decreased. By using the pretreatment for adding of the cation exchange resin, the recoveries of nitrate were $92-95 \%$ and the reduction efficiency decreased to $85-93 \%$ after ten samples measurements, which was not sufficient. On the other hand, when the $\mathrm{NaOH}-\mathrm{ZnSO}_{4}$ deproteinization of the standard solutions containing L-cystine is carrying out, L-cystine reacts with $\mathrm{Zn}^{2+}$ in the deproteinization agent easily as well as reacting with cadmium in the reduction column; and then can form some $\mathrm{Zn}$-(L-cystine) complexes, which can be easily coprecipitated together with $\mathrm{Zn}(\mathrm{OH})_{2}$ formed from $\mathrm{NaOH}$ and $\mathrm{ZnSO}_{4}$. For assuring these reactions, the components contained in the supernatant of the pretreated solutions were examined by using HPLC. The peaks of L-cystine disappeared on the HPLC chromatogram after deproteinization; this indicates that L-cystine was removed from the sample solutions by using the $\mathrm{NaOH}-\mathrm{ZnSO}_{4}$ method. As a result, the interference from the compounds containing sulfur atom was found to be eliminated by the $\mathrm{NaOH}-\mathrm{ZnSO}_{4}$ method. The peak height of nitrate was found to be recovered quantitatively and the reduction efficiency was kept at more than $98 \%$ after ten injections (Fig. 6B). Figure 7 shows the results for the standard addition method for nitrate in typical cell culture medium samples. These results demonstrated that the added nitrate was recovered quantitatively. The $\mathrm{NaOH}-\mathrm{ZnSO}_{4}$ deproteinization method was found to be effective not only for serum and plasma samples containing various proteins but also for the cell culture

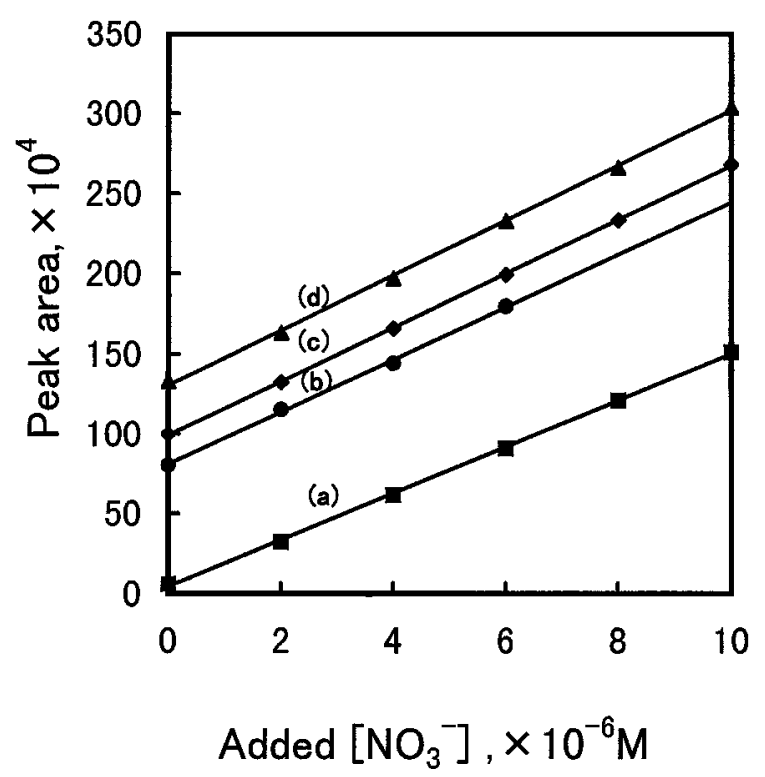

Fig. 7 Calibration graphs for the standard addition method with using cell culture medium samples by the $\mathrm{NaOH}-\mathrm{ZnSO}_{4}$ deproteinization. (a): standard solution of nitrate; (b): Dulbecco's Modified Eagle Medium sample 1; (c): Eagle's Minimum Essential Medium; (d): Dulbecco's Modified Eagle Medium sample 2. 
medium samples containing amino acids with interfering sulfur-atoms.

The proposed flow-injection spectrophotometric method enabled us to determine nitrite and nitrate in biological samples with high sensitivity, accuracy and reproducibility by using a diazotization/coupling reaction and adopting a highly effective reduction column coupled with the improved carrier solution. The $\mathrm{NaOH}-\mathrm{ZnSO}_{4}$ deproteinization method was the most effective for all of the various biological samples of the pretreatment methods, and was especially effective for removing the interfering compounds containing sulfuratoms through the reaction between $\mathrm{Zn}^{2+}$ in the deproteinization agent and sulfur-atoms of coexisting substances in biological samples.

We thank Ms. Akiko Inoue and Mr. Hiromitsu Tamanouchi of Tokyo Kasei Kogyo Co. Ltd. for their assistance throughout this work.

\section{References}

1. R. M. J. Palmer and S. Moncada, Biophys. Res. Commun., 158, 348 (1989).

2. S. Moncada, R. M. J. Palmer and E. A. Higgs, Pharmacol. Rev., 43, 109 (1991).
3. T. Malinski and Z. Taha, Nature [London], 358, 676 (1992).

4. J. F. Kerwin, Jr., J. R. Lancarster and P. L. Feldman, J. Med. Chem., 38, 4343 (1995).

5. M. A. Keln and J. Schrader, Circ. Res., 66, 1561 (1990).

6. Y. Ôyanagi, "NO and Medicine-Physiology and Pharmacology of Nitric Oxide (in Japanese)", p. 9, Kyoritsushuppan, Tokyo, 1993.

7. L. Anderson, Anal. Chim. Acta, 110, 123 (1979).

8. M. F. Gine, H. Bergamin F $^{\circ}$, E. A .G. Zagatto and B. F. Reis, Anal. Chim. Acta, 114, 191 (1980).

9. J. Ruzicka and Hansen, Anal. Chim. Acta, 114, 19 (1980).

10. J. F. van Staden, Anal. Chim. Acta, 138, 403 (1982).

11. S. Nakashima, M. Tagi, M. Zenki, A. Takahashi and K. Tôei, Bunseki Kagaku, 31, 732 (1982).

12. S. Nakashima, M. Tagi, M. Zenki, A. Takahashi and K. Tôei, Fresenius' Z. Anal. Chem., 319, 506 (1984).

13. L. C. Green, D. A. Wagner, J. Glogowski, P. L. Skipper, J. S. Wishnok and S. R. Tannenbaum, Anal. Biochem., 126, 131 (1982)

14. K. Higuchi, R. Yamazaki, A. Inoue and Y. Ogawa, Proceedings of Separation Sciences '95, Tokyo, June 1995, p. 101.

15. Japanese Industrial Standard K0102 (1993).

16. M. Somogyi, J. Biol. Chem., 160, 69 (1945).

17. N. Nelson, J. Biol. Chem., 153, 375 (1944).

(Received September 4, 1998)

(Accepted November 18, 1998) 